\title{
PROCESSO DE RESSIGNIFICAÇÃO DA GEOGRAFIA DO PANTANAL
}

\author{
the reframing process of the Pantanal geography \\ Mara Aline Santos Ribeiro* \\ Edvaldo César Moretti**
}

\begin{abstract}
Resumo
Desde o final do século passado o Pantanal está passando por transformações em sua geografia. A crise nas atividades agropecuárias, o avanço das comunicações e da tecnologia, aliado ao advento do turismo na década de 1970, alterou o modo de produção no Pantanal. Dentre as mudanças que aconteceram, as voltadas às atividades profissionais emergiram com destaque nesse estudo que tem como principal objetivo, discutir as principais transformações provocadas pelo turismo e pela modernização da pecuária nas relações de trabalho do Pantanal, que repercutem diretamente no modo de vida da população local. A análise das entrevistas e dos aspectos levantados na observação da paisagem utiliza, a geografia como reveladora do movimento da sociedade que está se transformando no Pantanal para atender a demanda do turismo e a modernização da pecuária, alicerçado nas relações econômicas, sociais e culturais.
\end{abstract}

Palavras-chaves: Geografia, Pantanal, Gente pantaneira, Trabalho.

\begin{abstract}
Since the end of last century, Pantanal is undergoing changes in its geography. The crisis in farming, advances in communications and technology, coupled with the advent of tourism in the 1970s, changed the mode of production in the Pantanal. Among the changes that happened, the activities aimed at practitioners emerged prominently in this study, which aims to discuss the main changes caused by tourism and modernization of livestock in the labor relations of the Pantanal, which directly affect the livelihood of local people. The analysis of interviews and observation of the landscape uses geography as revealing the movement of society that is becoming the Pantanal to meet the demands of tourism and modernization of farming, based on economic, social and cultural rights.
\end{abstract}

Key words: Geography, Pantanal, Pantanal people, Work.

\begin{abstract}
Resumen
Desde finales del siglo pasado, el Pantanal está experimentando cambios en su geografía. La crisis en la agricultura, los avances en las comunicaciones y la tecnología, junto con la llegada del turismo en la década de 1970, cambió el modo de producción en el Pantanal. Entre los cambios que han ocurrido, las actividades dirigidas a los profesionales surgió un lugar destacado en este estudio, cuyo objetivo es analizar los principales cambios causados por el turismo y la modernización de la ganadería en las relaciones laborales del Pantanal, que afectan directamente el sustento de la población local . El análisis de las entrevistas y la observación del paisaje utiliza la geografía que nos mostró el movimiento de la sociedad que se está convirtiendo en el Pantanal para satisfacer las demandas del turismo y la modernización de la agricultura, basada en los derechos económicos, sociales y culturales.
\end{abstract}

Palabras clave: Geografía, Pantanal, la gente Pantanal, Trabajo.

(*) Doutoranda do Instituto de Geografia da Universidade de Campinas, Prof ${ }^{a}$. Msc. da Universidade Federal de Mato Grosso do Sul - Cidade Universitária, Caixa Postal 649, Prédio do CCHS - CEP 79.070-900, Campo Grande (MS) - Brasil, Tel: (+55 67) 3345-7585 - mara_aline@yahoo.com.br.

(**) Bolsista Produtividade CNPq, Prof. Dr. da Pós-Graduação em Geografia da Universidade Federal da Grande Dourados Rodovia Dourados-Itahum, km 12. Prédio da FCH, Cidade Universitária, CEP: 79.804-970 - Dourados (MS) - Brasil, Tel: (+ 55 67) 34113904 - ecmoretti@hotmail.com. 


\section{INTRODUÇÃO}

O Pantanal Sul Mato-grossense, passou por representativas transformações em sua geografia nos últimos quarenta anos. Esse artigo tem por objetivo discutir a ressignificação da geografia pantaneira, baseada nas novas relações de trabalho advindas do turismo e da modernização da pecuária no Pantanal que repercutem diretamente nos modos de vida da população local.

Os registros de ocupação do Pantanal contam desde o século XVII, indígenas, portugueses, espanhóis, paraguaios, bolivianos e os Bandeirantes paulistas, entre outros construíram e reconstruíram o território pantaneiro ao longo desses anos. O trabalho da população pantaneira em referência é posterior à ocupação do Pantanal pelas sociedades indígenas que desenvolveram outras atividades.

No final dos anos de 1970 iniciou-se no Pantanal um período de grandes mudanças que culminaram, nos primeiros anos do século XXI, com a ascensão do turismo e a modernização da pecuária, impondo ao Pantanal novas relações socioeconômicas e novos atores, os empresários da pecuária modernizada e os profissionais do turismo. Esse reordenamento interferiu diretamente no território e na territorialidade pantaneira.

O Pantanal é dividido em propriedades privadas da terra conhecidas por fazendas, que até meados do século XX praticavam, em sua maioria, exclusivamente a pecuária extensiva de corte. A crise da atividade pecuária desencadeada nesse período, em consonância com o advento do turismo de pesca, fez com que os fazendeiros vislumbrassem o turismo como uma atividade alternativa na complementação dos lucros.

A partir de então, o território pantaneiro foi sendo reorganizado para transformar os chamados recursos locais em produtos turísticos. Como exemplo, o ajustamento das fazendas para implantação das pousadas pantaneiras. Muitas vezes, as próprias sedes das antigas fazendas são adaptadas para a função de meio de hospedagem.

A hidrografia da região, os rios piscosos e navegáveis em quase toda extensão, oportunizaram no Pantanal o turismo de pesca. A prática dessa atividade durante longo período no Pantanal provocou impactos ambientais e sociais quase irreversíveis. Em decorrência, na segunda metade dos anos de 1990, foram implantados programas e ações de incentivo ao chamado turismo contemplativo. Para Moretti (2002), independentemente do tipo de turismo praticado na região, as transformações espaciais sempre ocorrerão, pois, é próprio das atividades econômicas procurarem valorizar determinados aspectos da construção social e desvalorizar aquelas que não são necessárias para sua dinâmica produtiva.

[..], o turismo constitui-se em uma das atividades que atrai maior volume de investimentos de capitais, principalmente quanto à produção deste espaço, visando ao consumo do ambiente natural - mas um ambiente produzido e preparado para atender às necessidades do turista urbano - portanto, produz custos ambientais e sociais (MORETTI, 2002, p .63).

Concomitante ao crescimento do turismo, o avanço tecnológico do sistema de comunicação e de transporte na região e as exigências do mercado globalizado, fizeram com que a pecuária, principal atividade econômica do Pantanal, se modernizasse (Figura 1).

Novas técnicas de manejo do gado demandaram a inserção de outros atores na lida do gado, as tradicionais fazendas pantaneiras, em sua grande maioria, sofreram mudanças na forma de trabalhar o gado. Atualmente, as empresas pecuárias são gerenciadas por administradores de empresas e o rebanho fica aos cuidados de técnicos agropecuários orientados por médicos veterinários e zootecnistas (Figura 2). Aos poucos, o trabalho no campo que o pantaneiro executava a cavalo, está sendo substituído por motocicletas, triciclos e caminhonetes, novas máquinas e equipamentos vão sendo introduzidos (Figura 3).

A nova configuração das propriedades no Pantanal e a expansão do mercado da carne bovina no país, passou a exigir produtos de melhor qualidade, levando a produção pecuária à agregar novas técnicas para mantê-las competitivas no mercado. 


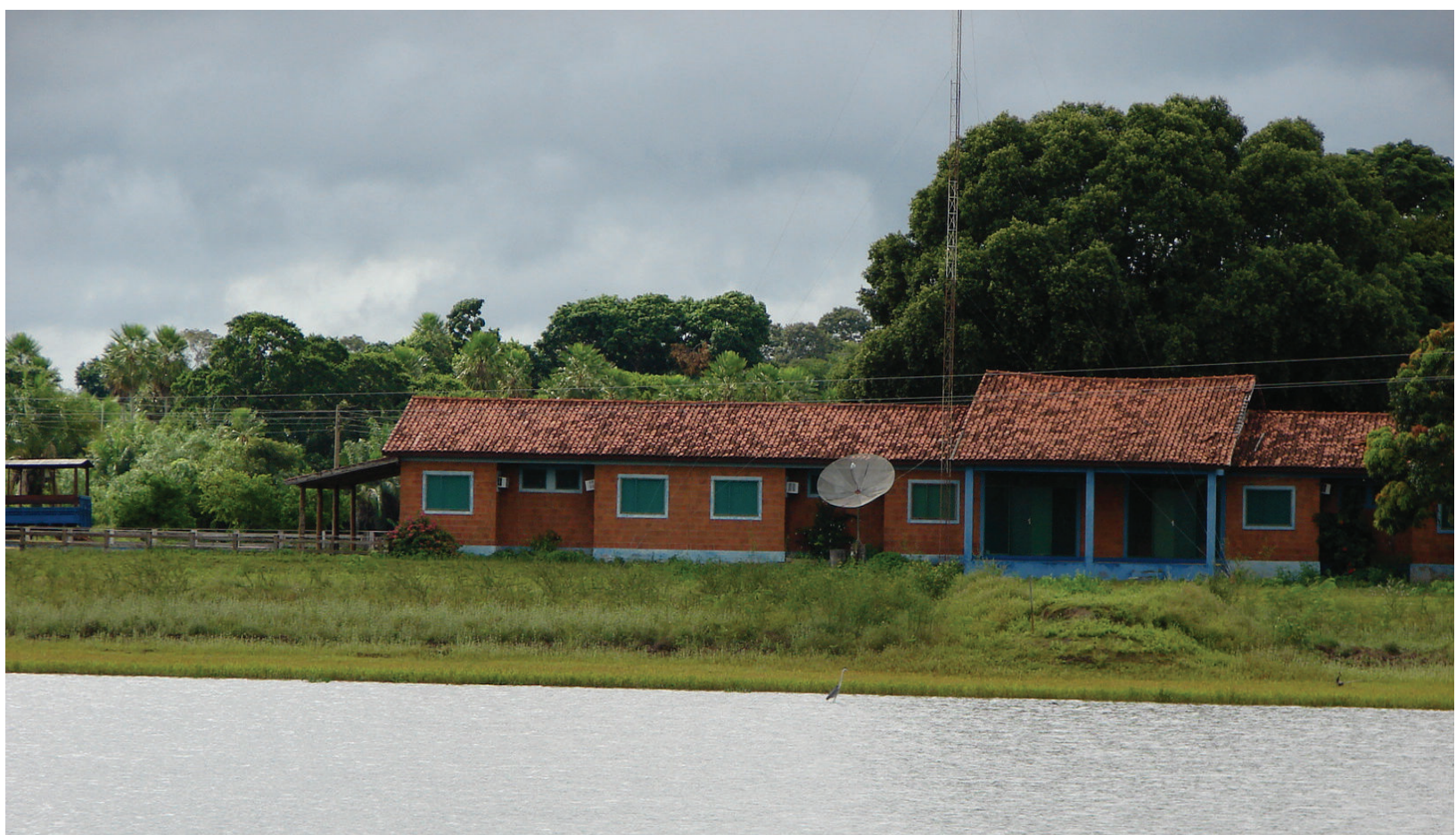

Figura 1 - Pousada no Pantanal, destaque antena parabólica e aparelhos de ar condicionadois. Autora: RIBEIRO, M. A. março 2002.

Um dos exemplos das novas práticas na pecuária é a alimentação do gado, que há alguns anos era feita com a vegetação nativa e suplementada apenas com sal, atualmente os animais estão recebendo suplementação nutricional, constituída principalmente de mistura mineral. Em uma entrevista, FP - nesse artigo os entrevistados são identificados pelas iniciais com o objetivo de resguardar as identidades - afirma que: “Algumas empresas pecuárias, aos poucos, estão fornecendo concentrados proteicos para animais jovens, para acelerar o desenvolvimento e procedendo a terminação dos animais em confinamento, com acompanhamento de médicos veterinários e zootecnistas”.

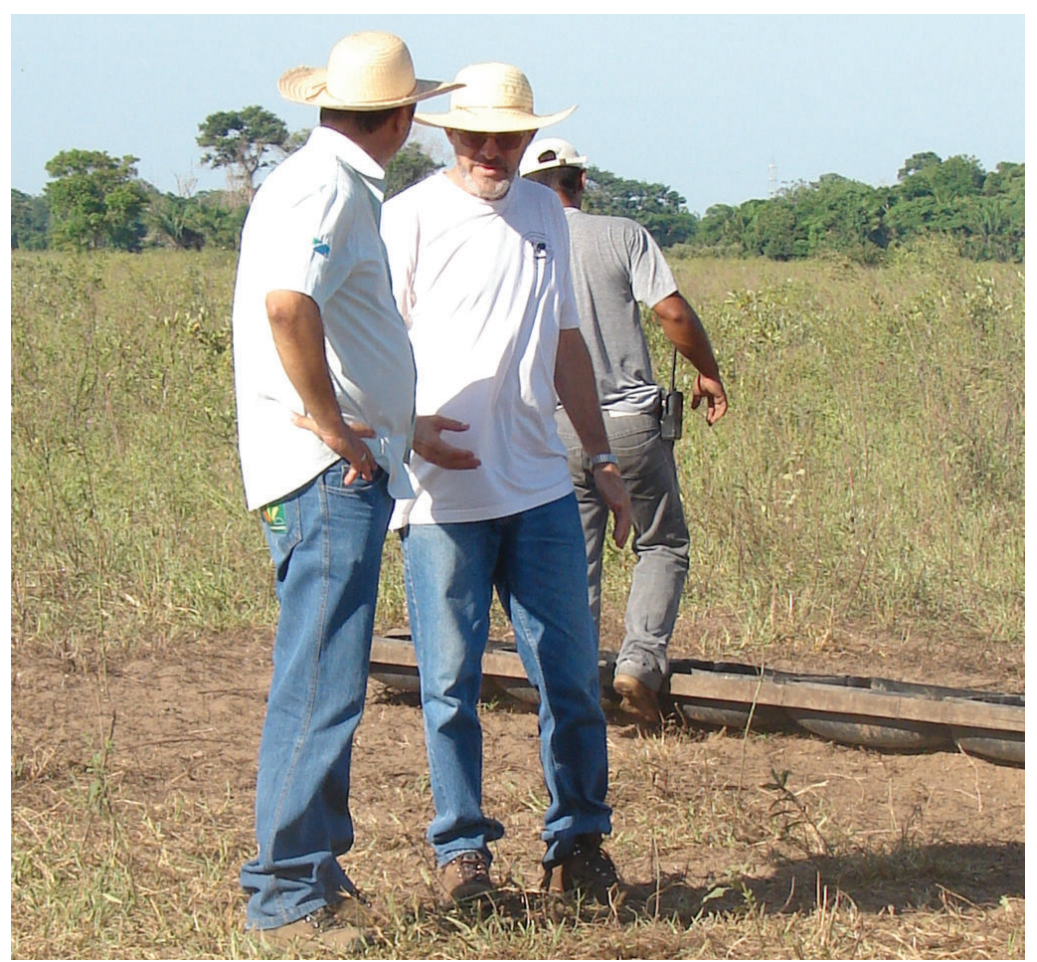

Figura 2- Gerente de empresa pecuária, médico veterinário e em segundo plano peão. Autora: RIBEIRO, M. A. fevereiro 2011. 


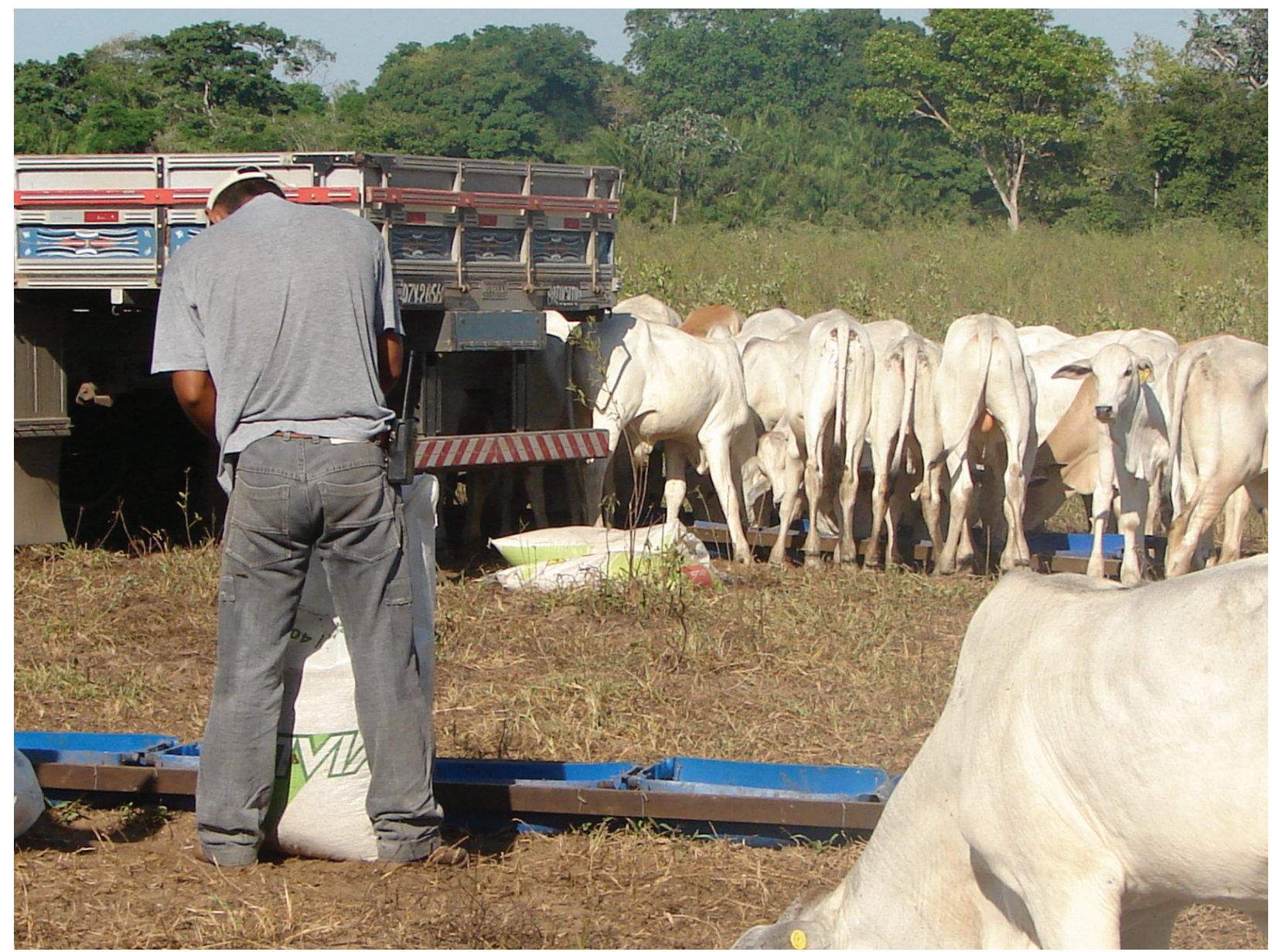

Figura 3 - Peão pantaneiro na lida com o gado, destaque: equipamentos de comunicação, transporte, uniforme da empresa e cocho para suplementação da alimentação animal.

Autora: RIBEIRO, M. A. fevereiro 2011.

É nesse universo de transformações que a geografia do Pantanal se ressignifica em sua forma e função, ancorada nas novas tecnologias, nos novos modos de produção e no novo modo de viver das "gentes pantaneiras" - expressão utilizada no texto como referência às pessoas que vivem no Pantanal, aos vários grupos, à multicultura, à diversidade e as diferentes classes sociais que compõem a cultura pantaneira.

\section{NOVOS MODOS DE PRODUÇÃO NO ESPAÇO PANTANEIRO: turismo e pecuária}

As pessoas que vivem no Pantanal, ao longo do tempo, vão adquirindo experiências ambientais que as habilitam interpretar os ciclos da natureza, tais como, os períodos de cheia ou de seca, o comportamento e identificação dos sons dos animais, a época de florada das plantas e as ameaças que as ações humanas representam para aquele lugar.

Para a população local, cada elemento da paisagem, como, por exemplo, um rio, uma ponte, uma árvore, a sede de uma fazenda, possui um significado que o identifica com o território. Tais significados podem ser também considerados como simbologias, denominados de geossímbolos por Bonnemaison (2002) após entrevistar as moradoras de uma vila:

Elas [moradoras de uma vila] me indicavam os lugares, os rochedos, os bosques de arvoredos, os caminhos: cada um deles tinha um nome e possuía um sentido. Depois, terminei por compreender que esses lugares eram geossímbolos: eram a verificação terrestre de mitos, a fonte de poderes cósmicos e os fundamentos da organização social. Essa geografia sagrada desenhava na terra as letras de uma linguagem simbólica, uma espécie de escrita codificada a partir da qual o grupo lê, difunde e reproduz sua própria visão de mundo (BONNEMAISON. 2002 p. 123). 
Por isso, o Pantanal, na visão das gentes pantaneiras, está pleno de geossímbolos.

A produção do espaço pelo trabalho é um dos elementos transformadores da paisagem em sua forma ou função, como as pontes, as estradas, as edificações que, com suas funções específicas, passaram a compor a paisagem pantaneira.

O trabalho da população pantaneira, até meados do século passado, era quase que exclusivamente voltado à lida com o gado, com relações sociais e profissionais engendradas na família. Normalmente os casais se formavam na própria fazenda, onde trabalhavam, criavam os filhos no local e naturalmente eram treinados para assumirem o trabalho com o gado. As relações de compradio sempre foram comuns no Pantanal e podem ser consideradas formas sutis de submissão dos empregados aos patrões.

A implementação do turismo alterou o modo de vida e de produção no Pantanal. As "gentes" do Pantanal, caracterizadas por hábitos simples e de pouco contato com o "mundo externo", começaram, em um curto período de tempo - cerca de trinta anos - a conviver com pessoas das mais diferentes nacionalidades, culturas, línguas e objetivos - os turistas. Está havendo um processo de ressignificação do modo de vida das pessoas, novas experiências sociais, culturais e econômicas, estão reconstruindo a história local em um movimento cíclico e dialético. A população precisa se moldar à nova ordem econômica e social e criar novos hábitos e costumes, sob pena de ficar à parte do processo econômico e social vigente. No que se refere aos novos modos de produção e o trabalhador, Williams (1989) considera que "A inclusão do trabalho e, portanto, dos trabalhadores, [é vista como] uma mudança consciente de identificação" (WILLIAMS, 1989, apud VARGAS, 2009, p. 252).

A atividade turística no Pantanal atraiu profissionais de outras regiões que, no geral, apresentaram dificuldades em se adaptar ao trabalho e ao local, por diversos fatores, como as dificuldades de transportes e comunicação decorrentes das grandes distâncias entre as fazendas - onde se localizam as pousadas - e as áreas urbanas. Sendo assim, a mão de obra nativa assume importantes papéis no trabalho com o turismo.

Um empresário do turismo afirma que:

O pessoal que vem de fora o máximo, máximo que eles conseguem ficar são seis meses, são pessoas formadas e eles vêm com aquela expectativa, eles vêm com paixão, mas na hora que chega e eles vêem a realidade do isolamento, da rotina, é seis meses o máximo, não aguenta, o pessoal que é formado na faculdade vem tudo com a teoria, bonitinho, a hora que chega aqui e enfrenta esse mundão (JR).

O entrevistado revela as dificuldades encontradas pelos profissionais urbanos, oriundos de escolas voltadas para a formação em turismo ou área afim, que, ao deparar-se com a realidade local, encontram dificuldades em fixar-se.

Por sua vez, "as gentes pantaneiras" estão adaptadas à vida do Pantanal, isso os credencia como potenciais profissionais do turismo, desde que treinados para o exercício da nova profissão. O mesmo entrevistado ressalta: "[os pantaneiros] são os caras que mais conhecimento tem, pode ser biólogo, ecólogo, ter o conhecimento que for que o cara chega aqui e não fica" (JR).

O proprietário de uma pousada complementa:

"Funcionário só pantaneiro. O Pantanal, na verdade é para quem entende. Não tem condições de pegar uma pessoa da cidade e colocar lá, ele não vai adequar. Logo que chega acha lindo, mas viver num isolamento, naquela nostalgia não é fácil aguentar" (JJ).

Nesta fala, é possível apoiar-se na certificação de Bonnemaison quando se refere ao encontro entre homem, conhecimento e lugar, pois, para ele, "O sentido último da abordagem cultural em geografia está, sem dúvida, em reencontrar a riqueza e a profundidade da relação que une o homem aos lugares" (BONNEMAISON, 2002, p. 108). 
Assim, gradativamente, os pantaneiros vão sendo incorporados ao novo ordenamento profissional atuando, no geral, em atividades subalternas que demandam conhecimento local, como cozinheira, camareira, motorista, piloteiro, guia de turismo, monitor ambiental, dentre outras, promovendo a possibilidade da permanência no Pantanal como trabalhador.

A despeito das dificuldades de adaptação ao novo ordenamento profissional, a renda das famílias aumentou com o salário somado às "gorjetas" (salário fixo e renda extra), fortalecendo a economia familiar. Antes da implementação da atividade turística, muitos desses pantaneiros hoje dedicados ao turismo, mantinham-se "reféns" dos armazéns das grandes fazendas que consumiam parte da remuneração mensal. E mesmo com as dificuldades e dos desafios de uma "nova" profissão, o setor de serviços está em expansão na região e percebe-se muita expectativa por parte das "gentes pantaneiras" com a atividade que aflora.

Os trabalhadores do turismo no Pantanal têm um novo olhar para o ambiente, um olhar mercantil que o entende como um produto turístico, diferente dos olhares de trinta ou quarenta anos atrás, no qual o ambiente era compartilhado e não vendido. De acordo com um dos entrevistados, os turistas querem conhecer os animais e as plantas, ou seja, eles querem comprar amostragem da fauna e da flora pantaneira.

Para que o produto turístico Pantanal esteja apto à venda é preciso mantê-lo com as características que lhe são peculiares, assim, se faz necessário um serviço de monitoramento do desenvolvimento do turismo no local. Esse é um dos motivos pelos quais alguns trabalhadores do turismo às margens da Estrada-parque Pantanal cobram rigor na fiscalização por parte dos órgãos competentes, uma das reivindicações é que os serviços sejam prestados por guias de turismo, motoristas e monitores ambientais devidamente qualificados e credenciados pela EMBRATUR, para exercer a atividade na região. Um monitor ambiental entrevistado clama por fiscalização mais rigorosa, "[...] fizeram promessas que ia ter fiscalização na estrada, só pra monitores trabalhar, mas nunca aconteceu, até hoje nunca aconteceu. Hoje pode trabalhar, sem ter curso, sem nada, [...]" (PP).

Os cursos de qualificação profissional em turismo são oferecidos pelo Senac, pelo o governo do estado ou municipal. Os alunos são certificados e credenciados pela EMBRATUR, porém não há efetivo monitoramento da prática da atividade turística no Pantanal por parte dos órgãos competentes, conforme registro de entrevista realizada no Pantanal.

Mesmo com os problemas advindos do novo ordenamento socioeconômico do Pantanal, as gentes pantaneiras respondem estarem satisfeitas em trabalhar com o turismo, pois comparam com o trabalho anterior e o isolamento que experimentavam. Atribuem à nova atividade qualificação profissional, vantagens salariais, culturais e físicas, e almejam por capacitação, infraestrutura, fortalecimento da classe, instituição de sindicatos e associações. Para alguns a qualificação profissional e a oportunidade de conhecerem outras culturas são o diferencial no momento de optar entre o trabalho com o gado e o turismo.

Nas palavras dos entrevistados pode-se observar a satisfação da gente pantaneira com o novo formato da produção no Pantanal, e as expectativas da profissão. EB afirma que gosta do trabalho atual porque "[...] você acaba conhecendo pessoas do mundo inteiro e vários tipos de cultura muita coisa né que você aprende, tem a possibilidade de você ampliar seus horizontes". Na opinião da gerente ER é importante mais investimento na qualificação profissional "Eu acho que a gente tinha que ter mais suporte pra ter um treinamento, pois todo mundo que vem pra cá vem leigo, a não ser os guias que já são da região e tem uma noção".

A demanda pelo chamado turismo contemplativo aumentou o número de turistas estrangeiros no Pantanal e consequentemente as pousadas precisaram investir no treinamento de pessoal. $\mathrm{O}$ monitor ambiental PP considera importante o investimento que a pousada, onde ele trabalha, fez em qualificação profissional dos funcionários,

“[...] fiz curso de Monitor Ambiental em Corumbá pelo SENAC, fiz aqui na fazenda, o pessoal do SENAC de Corumbá veio dá pra nós aqui. E a fazenda também investiu, veio gente dá o curso de pilotagem, piloteiro de barco, para poder ter carteira e acesso no rio" (PP). 
O monitor ambiental TS considera o turismo um veículo de conhecimento para as pessoas que trabalham no Pantanal, ele considera "[...] muito importante outras culturas. Eu converso muito com eles (os turistas), quero saber sobre países, sobre a cultura deles, sempre pergunto muito sobre a cultura deles, porque eu sou muito curioso, tento aprender, quando é uma pessoa de outro país que agente não conhece. Tinha um casal da Iugoslávia, eu já que queria saber, acho que trocou de nome eu quero saber, eu sou muito cego em relação a isso, que queria saber tudo sobre aquilo lá, então eu perguntei muito" (TS).

As transformações na vida destas pessoas não ficaram restritas às relações de trabalho. A chegada de turistas estrangeiros ao Pantanal "obrigou" os ex-peões a comunicarem-se em outras línguas, como forma de sobrevivência. Alguns monitores ambientais que vivem e trabalham no Pantanal conseguem se expressar em outras línguas, conforme relatos:

"Só tinha europeu, tudo estrangeiro, não falava nada, só espanhol e eu não falava nada, acompanhava porque eu conhecia toda a região, sempre andei caminhava, voltava e comecei a aprender o espanhol, aí comecei a praticar o inglês, parei, não quis o inglês comecei a aprender o hebraico agora falo espanhol, inglês, hebraico e algumas palavras em alemão também. Mas só falo" (PP).

"Não aprendi a falar inglês em colégio nem nada. Hoje em dia podemos confirmar tudo certinho, na questão de inglês, espanhol, hebraico e um pouco de alemão consigo me comunicar totalmente" (AA).

Esta condição fez com que os trabalhadores do turismo, desenvolverem formas de comunicação e de expressão em outras línguas. A maioria dos entrevistados não é fluente em línguas estrangeiras, como o inglês ou o hebraico, mas conseguem comunicar-se nestas línguas. Ao incorporar palavras de língua estrangeira ao vocabulário, esse pantaneiro sente-se valorizado e assume uma posição privilegiada entre os colegas. Um guia, por exemplo, qualificou seu trabalho como excelente por conhecer palavras em inglês e italiano. Em conversa, demonstrou equivocadamente que as expressões "Let's go everybody" (em inglês) e "Andiammo" (em italiano), teriam o mesmo significado, qual seja, "Suba no trator". O interlocutor inclusive manifestou espanto diante do possível desconhecimento da pesquisadora sobre essas expressões. Nesse sentido, a linguagem, como uma das formas de identificação e pertencimento a um determinado grupo social, também se ressignifica na paisagem pantaneira. A linguagem, enquanto importante elemento cultural é rica em significados. A cultura, para Bonnemaison (2002):

[...] é tida como um tipo de resposta, no plano ideológico e espiritual, ao problema do existir coletivamente num determinado ambiente natural, num espaço e numa conjuntura histórica e econômica colocada em causa a cada geração. Por isso, o cultural aparece como a face oculta da realidade: ele é, ao mesmo tempo, herança e projeto. (BONNEMAISON, 2002, p.86).

Outros elementos culturais também vão sendo alterados como, por exemplo, a dieta pantaneira, tradicionalmente rica em proteína animal, necessária para manter os trabalhadores no campo, na lida com o gado, sob sol forte e calor intenso, durante horas. Com o turismo, aos poucos, foram sendo incluídos ao cardápio pantaneiro, legumes, verduras e frutas, alimentos pouco presentes no Pantanal - frutas, legumes e verduras não fazem parte da dieta pantaneira por serem pouco cultivados na região, além de serem perecíveis, não suportando o transporte a longas distâncias.

Um empresário da hotelaria sente-se responsável pela mudança na dieta de seus funcionários, "[...] ele tem comida boa, ele só vivia de arroz, feijão e carne e no jantar feijão, carne e arroz. Hoje ele tem verdura. A gente termina educando até a alimentação para ele“. (JJ).

E um ex-peão complementa ao se referir a alimentação "Mudou bastante, por exemplo, na fazenda não tem saladas, aqui (pousada) tem saladas, legumes. Lá era carne de sol, hoje tem freezer, eletricidade, mudou muito" (PP). 


\section{CONSIDERAÇÕES FINAIS}

As entrelinhas da aparente satisfação com a nova atividade profissional revelam a transformação da identidade profissional pantaneira. Ao questionar os entrevistados sobre a nomenclatura da atual profissão, faltaram-lhes palavras ao responderem que "mexem com turismo", mas foram unânimes em afirmar que anteriormente eram "peões". As "gentes pantaneiras" ainda não travaram uma relação de pertencimento com a nova profissão, porque não foi incorporada ao cotidiano pantaneiro, da mesma forma que o trabalho com o gado lhes pertence.

Porém, o retorno à atividade pastoril, a princípio não está nos planos dos atuais profissionais do turismo, nos questionamentos aos entrevistados sobre as pretensões para o futuro, a maioria disse que pretende viver o mais próximo possível da zona rural desenvolvendo outras atividades. Os monitores ambientais PP e TO pretendem trabalhar a terra, "Para o futuro o que eu quero, o que eu sonho para mim é um pedaço de terra, [...]. Tô guardando dinheiro, tô investindo, tô comprando" (PP). "Eu quero viver na beira do rio, quero pescar, verdade eu gostaria de ficar [...], pegar minha casinha, minha palafita na beira do rio, numa ilha, não quero ser governador de uma ilha, eu quero ficar junto com a natureza, com os bichos, eu já tô, só falta falar a língua deles” (TO).

A geografia como reveladora do movimento da sociedade está se transformando no Pantanal para atender a demanda do turismo e a modernização da pecuária, alicerçada nas relações econômicas, sociais e culturais. A comunidade pantaneira está construindo novas territorialidades que a identificará com o novo espaço. As transformações pelas quais as "gentes pantaneiras" e o Pantanal passaram nas últimas décadas inseriram novos elementos ao cotidiano pantaneiro, alteraram os construídos desde a chegada do não-indio e promove um processo de ressignificação da Geografia do Pantanal. O que era lento se movimenta com intensidade, reconstruindo a palavra do poeta, quando afirma: "As coisas que acontecem aqui, acontecem paradas. Acontecem porque não foram movidas. Ou então, melhor dizendo: desacontecem”. (BARROS, 1997, p.31).

\section{REFERÊNCIA BIBLIOGRÁFICA}

BARROS, M. Livro de pré-coisas: roteiro para uma excursão poética no Pantanal. $2^{\mathrm{a}}$ ed. Rio de janeiro; Record, 1997.

BERQUE, A. Paisagem-marca, paisagem-matriz: elementos da problemática para uma geografia cultural. In: CORREAA, Roberto Lobato \& ROZENDAHL, Zeny (orgs.). Paisagem, Tempo e Cultura. Rio de Janeiro: Eduerj, 1998.123p. p.84-91.

BONNEMAISON, J. Viagem em torno do território. In: CORREAA, R. L. \& ROZENDAHL, Z. (orgs.). Geografia Cultural: Um século (3). Rio de Janeiro: Eduerj, 2002.196p. p.83-131.

CABRAL, L. O. e BUSS, M. D. A paisagem como campo de visibilidade e de significação: um estudo de caso. Revista Espaço e Cultura N. 13. NEPEC/UERJ, Rio de Janeiro - Jan/Jun. 2002. p. 47-61.

CLAVAL, P. O papel da nova geografia cultural na compreensão da ação humana. In: CORRÊA, R. L. \& ROZENDAHL, Z. (orgs.). Matrizes da Geografia Cultural. Rio de Janeiro: Eduerj, 2001.144p. p. 35 - 86.

ROZENDAHL, Z. Campo e perspectivas da geografia cultural. In: CORREA, R. L. \& ROZENDAHL, Z. (orgs.). Geografia Cultural: Um século (3). Rio de Janeiro: Eduerj, 2002.196p. p.133-186.

CORREA, R. L. \& ROZENDAHL, Z. (orgs.). Paisagem, Tempo e Cultura. Rio de Janeiro: Eduerj, 1998.123p. p.92-123.

COSGROVE, D. A geografia está em toda parte: cultura e simbolismo nas paisagens humanas. In: CORREA, Roberto Lobato \& ROZENDAHL, Zeny (orgs.). Paisagem, Tempo e Cultura. Rio de Janeiro: Eduerj, 1998.123p. p.92-123

COSTA, O. Memória e paisagem: em busca do simbólico dos lugares.Revista Espaço e Cultura N. 15. NEPEC/UERJ, Rio de Janeiro - Jan/Jun. 2003. p. 33 - 40.

HAESBAERT, R. Territórios alternativos. 2. Ed., $1^{\mathrm{a}}$ reimpressão. - São Paulo: Contexto, 2009.

MOREIRA, R. Pensar e ser em geografia: ensaios de história, epistemologia e ontologia do espaço. $1^{\text {a }}$ 
ed., $1^{\text {a }}$ reimpressão. São Paulo: Contexto, 2008.

MORETTI, E. Paraíso visível e real oculto. Campo Grande, MS: Ed. UFMS, 2006.

NOGUEIRA, A. X. O que é Pantanal. São Paulo: Brasiliense, 1990.

RIBEIRO, M. A. Pantanal-MS: Turismo e pousadas. In: PANOSSO NETTO, A. \& MARQUES, H. R. Reflexões em Turismo: Mato Grosso do Sul. Campo Grande: Ed. UCDB, 2004.

SANTOS, Douglas. O que é Geografia? Inédito. Apostilado. 2007

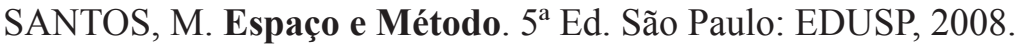

SANTOS, M. Metamorfose do espaço habitado: Fundamentos teóricos e metodológicos da Geografia. 6. Ed. São Paulo: EDUSP, 2008.

SANTOS, M. Natureza do espaço. 4. ed. 5. reimpr. - São Paulo: EDUSP, 2009.

SANTOS, M. O dinheiro e o território. In: SANTOS, M. et al. Território, territórios - ensaios sobre o ordenamento territorial. 2.ed. Rio de Janeiro: DP\&A, 2006. p. 13.

SAUER, C. A morfologia da paisagem. In: CORREAA, R. L. \& ROZENDAHL, Z. (orgs.). Paisagem, Tempo e Cultura. Rio de Janeiro: Eduerj, 1998.123p. p.12-74.

SUERTEGARAY, D. M. A. Espaço geográfico uno e múltiplo. Revista Eletrónica de Geografía y Ciencias Sociales, Universidad de Barcelona, n. 93, 15 de julio de 2001.

VARGAS, I. A. Porteiras assombradas do paraíso. Campo Grande/MS. Ed. UFMS, 2010.

Trabalho enviado em setembro de 2011

Trabalho aceito em novembro de 2011 